\title{
Лікувальна тактика при травмах паренхіматозних органів черевної порожнини
}

\author{
О. В. Мазуренко \\ Національна медична академія післядипломної освіти імені П. Л. Шупика, м. Київ

\section{Tactics of treatment in traumas of parenchymatous abdominal organs}

\author{
O. V. Mazurenko \\ Shupyk National Medical Academy of Postgraduate Education, Kyiv
}

Впровадження в практику сучасних додаткових методів діагностики стало підставою для перегляду способів лікування травм паренхіматозних органів черевної порожнини (ЧП) та отримання доказів, що виконання лапаротомії гемодинамічно стабільним постраждалим з певними пошкодженнями паренхіматозних органів недоцільно 3 огляду на можливість застосовування інших методів лікування, зокрема нехірургічних (non-operated management - NOM), які передбачають клінічне спостереження і консервативне лікування у відділенні реанімації та інтенсивної терапії, лабораторні, у тому числі біохімічні, методи дослідження, серійне використання комп'ютерної томографії (КТ) тощо [1 - 3]. Наведену тактику надання медичної допомоги корегують, застосовуючи мініінвазивні методи лікування, зокрема ангіографію, емболізацію артерій, лапароскопію або лапаротомію, відповідно до: перше - керівних принципів S3 надання медичної допомоги травмованим на всіх етапах, зокрема в протишоковій палаті та на етапі хірургічного лікування; друге - Концепції «Нова золота година», яка визначає тривалість хірургічної операції з приводу тяжких травм не більше ніж одніеї години за рахунок застосування тактик damage-control sergury (DCS) та damage control resuscitation (DCR), що окреслюють проведення заходів інтенсивної терапії, включаючи застосування контрольованої гіпотензії, гемостатичної терапії, рекомбінантного фактора VIIa, кріопреципітату та транексамової кислоти; третє - Протоколу гемотрансфузій при великій кровотечі (Majory haemorrhage protocols - MHP) та Протоколу масивних трансфузій (Massive transfusion protocols - MTP), які передбачають співвідношення свіжозамороженої плазми та еритроцитарної маси 1:3 - 1:2, кріопреципітату та еритроцитарної маси 1:10 - 1:7, плазми, тромбоцитів та еритроцитів 1:1:1 [4-11].

Даний огляд літератури грунтується на результатах бібліографічного та семантичного методів дослідження з використанням ресурсу «Medline-PubMed free article». Пошук джерел інформації здійснено за ключовими словами: abdominal trauma, management, emergency care, hospital.
Визначено, що у 20 - 30\% пацієнтів з травмами виникають пошкодження органів ЧП, серед яких найчастішими є пошкодження селезінки (ПС) - у 10 - 30\% постраждалих, що характеризуються летальністю 6 - 7\% і не мають тенденції до зменшення впродовж останніх 20 років. Протокол надання медичної допомоги у разі госпіталізації до закладу охорони здоров'я гемодинамічно стабільного постраждалого з підозрою на ПС передбачає: рентгенографічне дослідження органів грудної порожнини; фокусоване ультразвукове дослідження (УЗД) при травмі (Focused Assessment with Sonography in Trauma - FAST); КТ органів ЧП із внутрішньовенним контрастуванням за схемою $[12,13]$.

Відповідно до ступеня тяжкості ПС дотримуються тактики лікування, висвітленої ще в 1995 р., а саме: NOM з ангіоемболізацією або без неї; органозберігаюча хірургічна операція (спленорафія); спленектомія [14 - 16]. Американською асоціацією хірургів травми (1994) розроблена шкала тяжкості травм селезінки (табл. 1).

Згідно з наведеною шкалою ПС I та II ступенів вважають малими, III - середніми або проміжними, IV та V - тяжкими $[17,18]$.

При ПС I, II ступенів застосовують нехірургічне лікування, яке передбачає клінічне та лабораторне спостереження; контрастне УЗД (Contrast Enhanced Ultrasound - CEUS) впродовж 48 - 72 год; КТ з контрастуванням.

Нехірургічне лікування ПС не застосовують у постраждалих віком старше 55 років, за наявності гемоперитонеуму понад 250 мл, пошкоджень інших органів ЧП, анатомічних особливостей васкуляризації селезінки. Протипоказаннями до проведення NOM також вважають гемодинамічно нестабільний стан хворого та швидкість кровотечі понад 500 мл/ год (за даними серійного УЗД). Позитивні результати нехірургічного лікування ПС I та II ступенів констатують у 91,6 - 95\% постраждалих, негативні - у 3 - 18\% [18 - 22].

У разі загрози двохмоментного розриву селезінки, екстравазації контрастної речовини або псевдоаневризми за даними КТ виконують емболізацію селезінкової артерії. Проте це втручання не позбавлене ускладнень. Лихоманка, плев- 


\begin{tabular}{|c|c|c|}
\hline Ступінь & Пошкодження & Ознаки \\
\hline \multirow[b]{2}{*}{1} & Гематома & Субкапсулярна, менше 10\% поверхні \\
\hline & Розрив & $\begin{array}{l}\text { Пошкодження капсули селезінки, незначна кровотеча, пошкодження паренхіми селезінки менше } \\
1 \text { см глибиною }\end{array}$ \\
\hline \multirow{2}{*}{ II } & Гематома & Субкапсулярна, 10 - 50\% поверхні \\
\hline & Розрив & Розрив паренхіми менше 5 см в діаметрі \\
\hline \multirow{4}{*}{ III } & \multirow{3}{*}{ Гематома } & Субкапсулярна, більше 50\% поверхні \\
\hline & & Розрив субкапсулярної гематоми або гематоми паренхіми \\
\hline & & Гематома паренхіми більше 5 см \\
\hline & Розрив & Більше 3 см в глибину або пошкодження судин трабекул \\
\hline IV & Розрив & Розрив сегмента селезінки або судин із деваскуляризацією значної частини (більше 25\%) \\
\hline \multirow{2}{*}{$\mathrm{V}$} & Розрив & Повне розтрощення селезінки \\
\hline & Судини & Повне пошкодження судин, яке призвело до деваскуляризації селезінки \\
\hline
\end{tabular}

\section{Таблиця 2. Шкала тяжкості ПП (за S. Rizoli i співавторами [29])}

\begin{tabular}{|c|c|c|}
\hline Ступінь & Пошкодження & Ознаки \\
\hline \multirow{2}{*}{ I } & Гематома & Субкапсулярна, не збільшується, менше $10 \%$ поверхні \\
\hline & Розрив & Пошкодження капсули, незначна кровотеча, пошкодження паренхіми, глибина розриву менше 1 см \\
\hline \multirow{3}{*}{ II } & \multirow{2}{*}{ Гематома } & Субкапсулярна, не збільшується, 10 - 50\% поверхні \\
\hline & & Всередині паренхіми, не збільшується, діаметр менше 2 см \\
\hline & Розрив & $\begin{array}{l}\text { Поверхневий розрив, активна кровотеча, глибина розриву паренхіми } 1 \text { - } 3 \text { см, довжина розриву } \\
\text { менше } 10 \text { см }\end{array}$ \\
\hline \multirow{4}{*}{ III } & \multirow{3}{*}{ Гематома } & Субкапсулярна, більше 50\% поверхні або збільшується \\
\hline & & Розрив субкапсулярної гематоми з активною кровотечею \\
\hline & & Розрив гематоми паренхіми більше 2 см або збільшення розриву гематоми \\
\hline & Розрив & Глибиною більше 3 см \\
\hline \multirow[t]{2}{*}{ IV } & Гематома & Розрив гематоми парехіми з активною кровотечею \\
\hline & Розрив & $25-50 \%$ частки печінки \\
\hline $\mathrm{V}$ & Розрив & Паренхіми більше 50\% частки печінки \\
\hline $\mathrm{VI}$ & Судини & Відрив печінки, пошкодження нижньої порожнистої вени, великих печінкових вен \\
\hline
\end{tabular}

рит, частковий інфаркт селезінки виникають після емболізації селезінкової артерії у 61,9\% пацієнтів; інфаркт, атрофія селезінки та відновлення кровотечі - у 28,5\%; кровотеча, яку неможливо зупинити, - у 11\%; абсцеси селезінки - у 4\%. Також під час нехірургічного лікування ПС I та II ступенів розвиваються нориці підшлункової залози. Кровотечу, яку неможливо зупинити, вважають показанням до виконання спленектомії або повторної емболізації селезінкової артерії [23, 24].

Невідкладну хірургічну операцію виконують пацієнтам 3 гемодинамічно нестабільним станом та наявністю вільної рідини в ЧП за даними УЗД. Хірургічне втручання також показане при ізольованих ПC IV та V ступенів або при поєднанні ПС з черепно-мозковою травмою. Лапароскопічну спленектомію застосовують при розривах паренхіми селезінки розміром до 3 см та помірною безперервною кровотечею або в разі збільшення гематоми селезінки. Після спленектомії для зменшення ризику виникнення інфекційних ускладнень хворим вводять вакцини проти збудників інфекційних захворювань, зокрема Streptococcus pneumonia (Polyvalent pneumococcal vaccine (Pneumovax 23), Haemophilus influenzae type B (Haemophilus influenzae b vaccine (HibTITER) тощо), та здійснюють тривале спостереження за перебігом імунодефіцитного стану [25 - 27].
Пошкодження печінки (ПП) виникають у 16 - 25,2\% постраждалих з поєднаною та ізольованою травмою живота та супроводжуються летальністю 17,1\% і частотою розвитку післятравматичних ускладнень 20,0\%. Найпоширеніша причина смертності хворих з ПП впродовж «раннього післятравматичного періоду» - масивна кровотеча, «пізнього» - сепсис та гострий респіраторний дистрес-синдром. Щодо постраждалих з ПП застосовують нехірургічне лікування, трансартеріальну емболізацію (ТАE) або хірургічну операцію, які обирають відповідно до Шкали тяжкості травм печінки (табл. 2) [28 - 32].

Нехірургічне лікування закритих ПП із застосуванням транексамонової кислоти вважають стандартним способом у гемодинамічно стабільних постраждалих, яке включає моніторинг кардіореспіраторного статусу, функціональних печінкових тестів, зокрема, рівнів білірубіну, аспартат- та аланінамінотрансфераз, коагулограми та виконання ретроградної ендоскопічної холангіопанкреатографії. Частота позитивних результатів нехірургічного лікування ПП сягає 90\%. Протипоказаннями до нехірургічного лікування постраждалих із закритими ПП є: вік старше 55 років; зниження показників артеріального тиску; ознаки перитоніту; потреба в проведенні масивних гемотрансфузій; високий ступінь тяжкості травми за шкалою ISS; на- 


\begin{tabular}{|c|c|c|}
\hline Ступінь & Пошкодження & Ознаки \\
\hline \multirow{2}{*}{ I } & Гематома & Контузія або гематома, яка не збільшується \\
\hline & Розрив & Немає \\
\hline II & Розрив & $\begin{array}{l}\text { Поверхневий розрив глибиною менше } 1 \text { см, ниркова миска та чашечки не пошкоджені, } \\
\text { ознак екстравазації сечі немає }\end{array}$ \\
\hline III & Розрив & Глибина більше1 см, пошкодження ниркової миски та чашечки ознак екстравазації сечі немає \\
\hline \multirow{4}{*}{ IV } & Розрив & Поширюється на ниркову миску або є екстравазація сечі \\
\hline & Судини & Пошкодження ниркових артерії і вени з ознаками кровотечі \\
\hline & Інфаркт & Сегментарні інфаркти нирки, які не пов'язані з розривом \\
\hline & Гематома & Субкапсулярна гематома нирки, яка збільшується \\
\hline \multirow{4}{*}{$\mathrm{V}$} & \multirow{3}{*}{ Розрив } & Розтрощена нирка \\
\hline & & Відрив сечовода \\
\hline & & Повний розрив або тромбоз ниркових артерії і вени \\
\hline & Судини & Відрив судин ниркових воріт - деваскуляризація нирки внаслідок пошкодження ниркових воріт \\
\hline
\end{tabular}

явність інших внутрішньочеревних пошкоджень (за даними КТ). Потреба виконання ангіоемболізації для зупинки рецидивуючої кровотечі при ПП виникає у 12 - 28\% пацієнтів [33-36].

У разі ангіографічного підтвердження активної кровотечі при ПП застосовують емболізацію з проведенням додаткового втручання у 13,5 - 24\% спостережень [37 - 39].

Показаннями до хірургічного лікування хворих із закритими ПП є: екстравазація контрастної речовини за результатами КТ; госпіталізація постраждалого до закладу охорони здоров'я в стані шоку, що спостерігають у 9 - 30\% пацієнтів із ПП [40].

Пошкодження нирок (ПН) констатують у 1 - 5\% постраждалих, медична допомога яким обгрунтовується за Шкалою тяжкості травм нирок (табл.3) та включає нехірургічне лікування, мініінвазивні способи, хірургічне лікування [41, 42]

Нині переважну більшість гемодинамічно стабільних хворих із закритими ПН I та деяких видів IV ступенів лікують нехірургічно. Проникаючі поранення нирок лікують нехірургічно у гемодинамічно стабільних пацієнтів у разі доведення відсутності, зокрема за результатами КТ, інших поранень внутрішніх органів. При травмі нирки III ступеня здійснюють ангіоемболізацію. При розривах нирок з екстравазацією контрастної речовини застосовують ендоурологічні або черезшкірні методи лікування.

При розривах нирки внаслідок тупої травми з деваскуляризованими сегментами NOM застосовують лише у гемодинамічно стабільних хворих за відсутності пошкодження сечовивідних шляхів.

При ПН III або IV ступеня є значний ризик відновлення кровотечі в найближчому періоді після травми.

В післятравматичному періоді, зокрема під час консервативного лікування розривів нирки IV ступеня з деваскуляризацією сегмента, у 1 - 7\% паціентів формуються уриноми, паранефральні абсцеси, лікування яких передбачає черезшкірне дренування, а частота відновлення кровотечі становить 13 - 25\%. Пацієнти з ПН потребують спостереження впродовж 3 міс, яке, зокрема, передбачає контроль показників загального аналізу сечі, оцінку ниркової функції та артеріального тиску [43 - 45].

Отже, запропонований огляд свідчить, що впродовж останніх десятиліть відбулися зміни лікувальної тактики при травмах перенхіматозних органів ЧП, зокрема, впроваджено спосіб нехірургічного лікування пацієнтів з травмами I, II ступенів тяжкості за даними КТ та застосовуються мініінвазивні хірургічні втручання у гемодинамічно стабільних пацієнтів.

Проте слід зауважити, що обов'язковою умовою нехірургічного лікування травм паренхіматозних органів визнають наявність відповідних ресурсів, зокрема, достатньої кількості медичного персоналу для постійного спостереження за станом хворого, необмеженого доступу до КТ-сканера та методів інтервенційної радіології, достатньої кількості донорської крові та ії препаратів, можливості виконання невідкладної операції в разі погіршення стану хворого. За відсутності наведених умов застосування NOM небезпечне і слід виконувати рутинне хірургічне втручання. Хворі з травмами органів ЧП, яких не було оперовано, потребують тривалого спостереження лікаря за місцем проживання та мають бути інформовані про суб'єктивні ознаки відновлення кровотечі.

Тяжка травма, стан шоку та нестабільні показники гемодинаміки постраждалого є прямими показаннями до виконання невідкладної хірургічної операції.

\section{References}

1. Edmund A, Neugebauer M, Waydhas C, Lendemans S, Rixen D, Eikermann M, Pohlemann T. The Treatment of Patients With Severe and Multiple Traumatic Injuries. Deutches Arzteblatt International. Clinical Practice Guideline. 2012;109(6):102-8. doi:10.3238/arztebl.2012.0102/

2. Gaspar B, Negoi I, Paun S, Hostiuc S, Ganescu R, Beuran M. Selective Nonoperative Management of Abdominal Injuries in polytrauma patients: a protocol only for experienced. Trauma Centers. MAEDICA - a Journal of Clinical Medicine. 2014 Jun;9(2):168-72. Available from: https:// www.ncbi.nlm.nih.gov/pmc/articles/PMC4296760/pdf/maed-09-168.pdf.

3. Baldoni F, Tugnoli G. What does it mean to be a trauma center? 1989-2009: results of the last year and review of 20 years experience in managing trauma patients. Ann Ital Chir. [Internet]. 2010; 81(1):65-8.

Available from: https://www.ncbi.nlm.nih.gov/pubmed/20593756.

4. Donaubauer B, Fakler J, Gries A, Kaisers UX, Josten C, Bernhard M. Interdisciplinary management of trauma patients: Update 3 years after implementation of the $\mathrm{S} 3$ guidelines on treatment of patients with severe and multiple injuries. Anaesthesist. 2014;63(11):852-64. doi: 10.1007/s00101014-2375-y

5. Lendemans S, Ruchholtz S. S3 guideline on treatment of polytrauma/severe injuries. Trauma room care. Der Unfallchirurg. 2012;115(1):14-21. doi: $10.1007 / \mathrm{s} 00113-011-2103-\mathrm{x}$. 
6. Rixen D, Steinhausen E, Dahmen J, Bouillon B. S3 guideline on treatment of polytrauma/severe injuries. Initial surgical phase: significance possibilities difficulties? Unfallchirurg. 2012;115(1):22-9. doi: 10.1007/s00113011-2104-9.

7. Newgard CD, Schmicker RH, Hedges JR, Trickett JP, Davis DP. Bulger E, et al. Emergency medical services intervals and survival in trauma: assessment of the "golden hour" in a North American prospective cohort. Ann Emerg Med. 2010;55(3):235-46.e4. doi: 10.1016/j.annemergmed.2009.07.024.

8. Cannon JW, Khan MA, Raja AS, Cohen MJ, Como JJ, Cotton BA, et al. Damage control resuscitation in patients with severe traumatic hemorrhage: A practice management guideline from the Eastern Association for the Surgery of Trauma. J Trauma Acute Care Surg. 2017;82(3):605-17. doi: 10.1097/ TA.0000000000001333.

9. Balvers K, van Dieren S, Baksaas-Aasen K, Gaarder C, Brohi K, Eaglestone $\mathrm{S}$, et al. Combined effect of therapeutic strategies for bleeding injury on early survival, transfusion needs and correction of coagulopathy. $\mathrm{Br}$ J Surg. 2017;104(3):222-9. doi: 10.1002/bjs.10330.

10. Khan S, Allard S, Weaver A, Barber C, Davenport R, Brohi K. A major haemorrhage protocol improves the delivery of blood component therapy and reduces waste in trauma massive transfusion. Injury. 2013;44(5):58792. doi: 10.1016/j.injury.2012.09.029.

11. Roberts I. Tranexamic acid in trauma: how should we use it? J Thromb Haemost. 2015;13(1):195-9. doi: 10.1111/jth.12878.

12. Stengel D, Rademacher G, Ekkernkamp A, Güthoff C, Mutze S. Emergency ultrasound-based algorithms for diagnosing blunt abdominal trauma.Cochrane Database Syst Rev. 2015 Sep14;(9). doi:10.1002/14651858. CD004446.pub4

13. Savatmongkorngul S, Wongwaisayawan S, Kaewlai R. Focused assessment with sonography for trauma: current perspectives. 2017;26 (9):57-62. doi: 10.2147/OAEM.S120145.

14. Jang T, Mathur M, Basrai Z. Focused Assessment with Sonography in Trauma (FAST). Medscape. 2017. Available from: https://emedicine.medscape. com/article/104363-overview

15.Van der Cruyssen, Manzelli Splenic artery embolization: technically feasible but not necessarily advantageous. World Journal of Emergency Surgery 2016;11:47. doi: 10.1186/s13017-016-0100-7.

16. Yorkgitis B.K. Primary Care of the Blunt Splenic Injured Adult. Am J Med. 2017;130(3):365.e1-365.e5. doi: 10.1016/j.amjmed.2016.10.010.

17. Demetriades D. 2012 Spleen Injury Grading. In: Vincent JL., Hall J.B. (eds) Encyclopedia of Intensive Care Medicine. Springer-Verlag Berlin Heidelberg. 2012. Available from: https://link.springer.com/referenceworkentry/ 10.1007\%2F978-3-642-00418-6_517\#CR1_517

18. Coccolini F, Montori G, Catena F, Klugeret Y, et al. Splenic trauma: WSES classification and guidelines for adult and pediatric patients. World Journal of Emergency Surgery. 2017;12:40. doi: 10.1186/s13017-017-0151-4.

19. Yiannoullou P, Hall C, Newton K, Pearce L, Bouamra O, Jenks T, et al. A review of the management of blunt splenic trauma in England and Wales: have regional trauma networks influenced management strategies and outcomes? Ann R Coll Surg Engl. 2017;99(1):63-9. doi: 10.1308/rcsann.2016.0325.

20. Olthof DC, Van der Vlies CH, Goslings J. CEvidence-Based Management and Controversies in Blunt Splenic Trauma. Current Trauma Reports March. 2017,3(1):32-7. doi: https://doi.org/10.1007/s40719-017-0074-2

21. Zarzaur Ben L, Rozycki Grace S. An update on nonoperative management of the spleen in adults . Trauma Surg Acute Care Open. 2017;2:1-7. doi:10.1136/tsaco-2017-000075.

22. Brillantino A, Iacobellis F, Robustelli U, Villamaina E, Maglione F, Colletti $\mathrm{O}$, et al. Non operative management of blunt splenic trauma: a prospective evaluation of a standardized treatment protocol. Eur J Trauma Emerg Surg. 2016;42(5):593-8. doi: 10.1007/s00068-015-0575-Z.

23. Shin-Chi Wu, Ray-Jade Chen, Albert D. Yang, Cheng-Cheng Tung, KunHua Le Complication Associated With Embolization in the Treatment of Blunt Splenic Injury. World Journal of Surgery.2008;32 (3):476-82. doi: 10.1007/s00268-007-9322-x.

24. Ekeh A, Khalaf S, Ilyas S, Kauffman S, Walusimbi M, Mccarthy MC. Complications arising from splenic artery embolization: a review of an 11-year experience. Am J Surg. 2013;205(3):250-4. doi: 10.1016/j.amjsurg.2013.01.003.

25.Crichton J, Naidoo K, Yet B, Brundage S, Perkins Z. The role of splenic angioembolization as an adjunct to nonoperative management of blunt splenic injuries: A systematic review and meta-analysis. J Trauma Acute Care Surg. 2017;83(5):934-943. doi: 10.1097/TA.0000000000001649
26. Ermolov AS, Tlibekova MA, Yartsev PA, Guliaev AA, Rogal MM, Samsonov VT, et al. Laparoscopic Splenectomy in Patients With Spleen Injuries.Surg Laparosc Endosc Percutan Tech. 2015;25(6):483-6. doi: 10.1097/ SLE.0000000000000207.

27. Bonanni P, Grazzini M, Niccolai G, Paolini D, Varone O, Bartoloni A, et al. Recommended vaccinations for asplenic and hyposplenic adult patients. Hum Vaccin Immunother. 2017;13(2):359-68. doi:10.1080/216455 15.2017.1264797.

28. Doklestić K, Djukić V, Ivančević N, Gregorić P, Lončar Z, Stefanović B, et al. Severe Blunt Hepatic Trauma in Polytrauma Patient - Management and Outcome. Srp Arh Celok Lek. 2015;143(7-8):416-22. doi: 10.2298/ SARH1508416D.

29. Rizoli S, Brenneman F, Hanna S, Kahnamoui K. Classification of liver trauma. HPB Surg . 1996;9:235-8. doi: 10.1155/1996/58383.

30. Moore E, Moore F. American Association for the Surgery of Trauma. Organ Injury Scaling: 50th anniversary review article of the Journal of Trauma. J Trauma. 2010; 69(6):1600-1. doi: 10.1097/TA.0b013e318201124e

31. Melloul E, Denys A, Demartines N. Management of severe blunt hepatic injury in the era of computed tomography and transarterial embolization: A systematic review and critical appraisal of the literature. J Trauma Acute Care Surg. 2015;79(3):468-74. doi: 10.1097/TA.0000000000000724.

32. Saverio S, Moore E, Tugnoli G, Naidoo N, Ansaloni L, Bonilauri S, et al Non operative management of liver and spleen traumatic injuries: a giant with clay feet. World Journal of Emergency Surgery. 2012;7:3. doi: 10.1186/1749-7922-7-3.

33. Melloul E, Denys A, Demartines N. Management of severe blunt hepatic injury in the era of computed tomography and transarterial embolization: A systematic review and critical appraisal of the literature. J Trauma Acute Care Surg. 2015;79(3):468-74. doi: 10.1097/TA.0000000000000724.

34. Stassen Nicole A., Bhullar Indermeet, Cheng Julius D, Crandall Marie, Friese Randall, Guillamondegui Oscar, et al. Nonoperative management of blunt hepatic injury: An Eastern Association for the Surgery of Trauma practice management guideline. Journal of Trauma and Acute Care Surgery. 2012;73 (5):288-93. doi: 10.1097/TA.0b013e318270160d

35. Cirocchi R, Trastulli S, Pressi E, Farinella E, Avenia S, Morales U, et al. Non-operative management versus operative management in high-grade blunt hepatic injury. Cochrane Database Syst Rev. 2015;4(8):CD010989. Available from: https://www.ncbi.nlm.nih.gov/pubmed/26301722.

36. Wallis A, Kelly MD, Jones L. Angiography and embolisation for solid abdominal organ injury in adults - a current perspective. World J Emerg Surg. 2010;5:18.Available from: https://www.ncbi.nlm.nih.gov/pmc/articles/PMC2907361/doi: 10.1186/1749-7922-5-18.

37. Barrie J, Jamdar S, Iniguez MF, Bouamra O, Jenks T, Lecky F, et al. Improved outcomes for hepatic trauma in England and Wales over a decade of trauma and hepatobiliary surgery centralisation. Eur J Trauma Emerg Surg. 2017: 1-8. Available from: https://doi.org/10.1007/s00068-017-0765-y.

38. Ptohis ND, Charalampopoulos G, Abou Ali AN, Avgerinos ED, Mousogianni I, Filippiadis D, et al. Role of Embolization of Solid Organ and Pelvic Injuries in Polytrauma Patients. Front Surg. 2017;7(4):43. Published online 2017 Aug 7. doi:10.3389/fsurg.2017.00043.

39. Morales Uribe CH, López CA, Cote JC, Franco ST, Saldarriaga MF, Mosquera J, et al. Surgical treatment of blunt liver trauma, indications for surgery and results. Cir Esp. 201492(1):23-9. doi: 10.1097/TA.0b013e318270160d

40. Perrin A, Grilo N, Meuwly JY, Jichlinski P Valerio. Management of genitourinary trauma. Rev Med Suisse. 2016;12(541):2072-6. Available from: https://www.ncbi.nlm.nih.gov/pubmed/28700152.

41. Bryan B, Voelzke, Laura Leddy The epidemiology of renal trauma. Androl Urol. 2014;3(2):143-9. doi: 10.3978/j.issn.2223-4683.2014.04.11.

42. Chiron P, Hornez E, Boddaert G, Dusaud M, Bayoud Y, Molimard B, et al. Grade IV renal trauma management. A revision of the AAST renal injury grading scale is mandatory. Eur J Trauma Emerg Surg. 2016;42(2):237-41. doi: $10.1007 / \mathrm{s} 00068-015-0537-5$.

43. Shewakramani S, Reed KC. Genitourinary trauma. Emerg Med Clin North Am. 2011;29(3):501-18. doi: 10.1016/j.emc.2011.04.009

44. Mingoli A, La Torre M, Migliori E, Cirillo B, Zambon M, Sapienza P, et al. Operative and nonoperative management for renal trauma: comparison of outcomes. A systematic review and meta-analysis Ther Clin Risk Manag. 2017;13:1127-38. doi: 10.2147/TCRM.S139194.

45. Shoobridge J, Corcoran N, Martin K, Koukounaras J, Royce P, Bultitude M. Contemporary Management of Renal Trauma. Rev Urol. 2011;13(2):6572. doi: $10.3909 /$ riu0512 